\title{
ASPECTOS DE HUMANIZAÇÃO DO SERVIÇO DE ENFERMAGEM NO HOSPITAL DO SERVIDOR PÚBLICO ESTADUAL DE SÃO PAULO
}

\author{
Ir. Maria Adjutrix Feldmann * \\ Santina Toniello ** \\ Ir. Dulce de Oliveira Azevedo ** \\ Deuzarina Delgado da Silva ** \\ Ione Dantas de Olievira **
}

I - Conceito e evolução histórica do humanismo e da humanização.

Humanização é o modo humano de ser, no sentido de sobrepujar a forma animal.

É, portanto, tudo que desperta o sentimento de solidariedade humana e concorre para facilitar a circulação do homem no mundo humano: é coordenar os interesses complementares; é dissolver as fricções e atritos; é alargar a zona de concordância entre os homens.

Em suma, é tolerância, benevolência, compreensão e respeito mútuo.

A humanização é corolário do humanismo.

- Humanismo é um antropocentrismo refletido que, partindo do ronhecimento do homem, tem por objetivo a valorização do homem e a solução dos problemas humanos. Compreende a assimilação dos valcres humanos sedimentados no curso da história. Nesta peregrinação através da história, ele guardou, em seu conteúdo conceptual, o espírito e a cultura das épocas que atravessou e das quais conservou as diversas denominações: humanismo "cristão" "clássico", "filosófico ou racionalista". Transcendente, por sua natureza, a todas as culturas particulares, ele se enriquece com os tesouros de saber acumulados pelas geraçōes e, apoiado sobre a experiência de todos os tempos, tende à realização do tipo ideal humano preconizado pela cultura.

* Diretora do Serviço de Enfermagem no H.S.P.E.

** Enfermeiras do H.S.P.E. de São Paulo. 
O que humaniza é o que cria nos indivíduos a vontade de respeitar os outros e de ajudá-los, em lugar de empregar, para si só, a. inteligência e conhecimentos.

O espírito humanístico é largo e compreensivo.

II - A humanização da enfermagem e o processo evolutivo.

A enfermagem, por sua natureza e tradição, é uma profissão eminentemente humanitária. No entanto, sabemos que apresentou, no curso de sua história, variações nos escores de qualidade e intensidade da humanização, de acordo com as suas fazes evolutivas.

$\mathrm{Na}$ atualidade, o mundo vive as realidades de crescente avanço tecnológico, mecanização, divisão do trabalho e especialização, decorrentes do progresso científico. A metodologia científica promove o domínio da racionalidade.

Nos grandes centros urbanos, onde se concentram a maioria dos recursos assistenciais, entre eles as instituições de saúde, predominam as interaçōes, formais, o individualismo, o utilitarismo, a ratinização e burocratização das funções.

Todos esses fatores contribuem para diminuir o espírito humanitário da sociedade atual, de acordo com a concepção tradicional de humanização.

A enfermagem não poderá fugir ao processo de evolução globa] da sociedade. Será mais ou menos lento, mas inexorável.

No Brasil estamos longe de uma enfermagem altamente mecanizada e especializada. No entanto, a burocratização e formalização das interações são fatos crescentes nos grandes hospitais. Particularmente a enfermeira está se distanciando cada vez mais do seu objetivo principal, que é o paciente.

Apesar do processo evolutivo das ciências e da tecnologia, a humanização continua sendo valor básico da enfermagem, configurando-se no ideal da profissão.

Aliás, não existe incompatibilidade ou antagonismo entre ciência, e ideal, entre humanização e racionalidade. Portanto deve-se procurar crescente adequação da ciência ou racionalidade como meio para se atingir um mundo cada vez mais humano.

Talvez se torne necessária uma atualização do conceito tradicional de humanização da enfermagem, de acordo com as necessidades e espectativas da sociedade atual.

III - Humanização do Serviço de Enfermagem do Hospital do Servidor Público Estadual

Pela humanização do Servidor de Enfermagem pretende-se alcançar entre os membros da equipe, maturidade emocional e boa estruturação da personalidade. 
O equilíbrio emocional e bom ajustamento da equipe, condiciona atendimento humano aos usuários do hospital.

A equipe de enfermagem, pelo fato de permanecer continuamente $\mathrm{em}$ contato com os pacientes, sofre mais os impactos dos problemas de relacionamento com os mesmos. Os pacientes, pelo maior grau de dependência com relação à enfermagem, também sofrem profundamente com a falta de humanização dos membros da equipe. Essa ação reflexa contribui para elevar o nível de tensão de ambas as partes. Por isso, os responsáveis pela organização do serviço devem ter sempre em mente a diferença que existe entre paciente e pessoal; o paciente é um hóspede temporário, enquanto cada membro da equipe é um hóspede permanente.

Havendo humanização do serviço com relação aos membros da equipe, estes terão maiores condições de apresentar comportamento humanitário, possibilitando a consecução dos objetivos:

- Proporcicnar aos usuários do hospital o máximo de satisfação e ajustamento.

- Eliminar atritos entre ambas as partes.

- Atender os pacientes e familiares de modo solícito e cortês, respeitando seus direitos como pessoa humana, sua personalidade e individualidade.

A proposição do tema "humanização da enfermagem". como assunto do Congresso, motivou a realização de um estudo exploratório da humanização do serviço de enfermagem do Hospital do Servidor Estadual de São Paulo.

O levantamento focalizou:

1. Fatores de humanização do ambiente de trabalho oferecidos aos funcionários pelo hospital.

2. Satisfação e ajustamento do pessoal de enfermagem na função e no ambiente de trabalho.

3. Auto-avaliação do atendimento humano aos pacientes e familiares.

4. Avaliação da humanização da enfermagem feita pelos pacientes.

5. Avaliação do atendimento humano feito pelos familiares dos pacientes.

O levantamento referente aos itens 2 a 5 foi feito através de questionário contendo, em primeiro lugar, perguntas que exigiram resposta global, não operacionalizada, e depois outras especificando variáveis julgadas importantes e feitas no sentido de testar a primeira parte.

1 - Fatores de humanização do ambiente de trabalho oferecidos aos funcionários pelo Hospital. 


\section{1 - Objetivos:}

- Obter harmonia, satisfação e realização profissional no trabalho.

- Desenvolver ao máximo as potencialidades do funcionário.

Atendê-lo da melhor maneira possível nos seus direitos como pessoa humana, respeitando-lhe a dignidade, personalidade e individualidade.

1.2 - Fatores de humanização em relação aos funcionários.

\subsection{1 - Promoção}

- Formação do Auxiliar de Enfermagem através de convênios mantidos com:

-.. Cruz Vermelha Brasileira (curso de 2 anos)

- Escola Paulista de Enfermagem (curso intensivo 1 ano)

Foram-se através destes convênios desde 1968, 118 auxiliares de Enfermagem, provindos das funções de Atendente de Enfermagem e Serventes.

1.2.2 - Readaptação do Auxiliar de Enfermagem a:

- Função da enfermeira - duas

- Auxiliar médico - cinco

- Técnico de Raio $\mathrm{X}$ - dois

- Eletroencéfalografia - um

- Eletrocardiografia - dois

1.2.3 - Readaptação de Atẹdente de Enfermagem a:

- Cinésioterapia

- Escriturário

- Auxiliar de Banco de Sangue

- Auxiliar de Laboratório clínico

1.3 - Atualização do Profissional. Programação para 19973.

Para Enfermeiras:

- Curso de Administração do Serviço de enfermagem em Terapia Intensiva

- Curso de Relações Humanas no Trabalho

- Curso de Relações Públicas

- Curso de Atualização em enfermagem médico-cirúrgica 
Para Auxiliar de Enfermagem:

- Curso de Instrumentação Cirúrgica

- Curso de Atualização em Enfermagem Obstétrica

- Curso de Relações Humanas no Trabalho

Para Atendentes de Enfermagem:

- Curso de Noções sobre puericultura

- Curso de Relações Humanas no Trabalho

- Curso de Enfermagem no Lar

Para Escriturários:

- Curso de Relações Humanas no Trabalho

- Curso de Relações Públicas.

1.4 - Facilitação para estudo na Comunidade.

Estabelecido horários especiais, procura-se atender tanto quanto possivel os funcionários interessados em estudar.

Horários especiais de trabalho:

Manhã

7:00 às 13:20

8:00 às 17:00

10:00 às 19:00

$6: 00$ às 15:00

7:00 às 19:00
Tarde

$13: 30$ às $22: 30$

12:00 às $21: 00$

13:00 às 19:20

$18: 30$
Noite

19:00 às 7:00

22:15 às 7:15

24:00 àsh 8:00

$18: 00$ às $6: 00$

1.5 - Reeducação dos funcionários em vez de demissão para alcançar:

- Maior habilidade técnica

- Disciplina e auto-controle

- Integração à equipe de trabalho.

Este trabalho é realizado através de:

- Transferência para outra clínica

- Orientação do Setor de Educação em Serviço de através de retreinamento 
1.6 - Atendimento em suas necessidades particulares durante o trabalho

- Saídas antecipadas por razões diversas

- Justificativas de faltas em casos de doenças dos familiares

Trocas de folgas para atendimento de casos especiais.

- Possibilidades de entrevista

- Licenças para viagens; preparo de exames, e em casos de prematuridade (a mãe pode ficar com seu filho conforme o caso mais 1 ou 2 meses)

- Ajuda na alimentação através de um pagamento simbólico de Cr\$ 2,C0 (almoço ou jantar)

1.7. - Condições de ambiente de trabalho.

- Vestiários com armários individuais

- Possibilidade de tomar banho após a jornada de trabalho

- Sala de recreação e descanso (jogos de mesa, jogos de pinguepongue)

- Sala de televisão

- Biblioteca (aberta das 6:00 às 23:00 horas)

- Uniforme fornecido pelo Hospital

-- Assistência Médica para funcionários e seus dependentes

- Pagamento para todos os funcionários, do risco de insalubridade, mesmo cs que não tem contato direto com o paciente

- Remuneração adequada a:

- Enfermeira

- Técnico de Enfermagem

- Auxiliar de Enfermagem

- Atendente de Enfermagem

- Servente

1.8 - Atendimento em suas necessidades sociais

a. Possibilidade de Turismo através da $A F I A M S P E$.

b. Promoção de festas

- Aniversários mensais

-- Semana da Enfermagem

- Dia do Enfermo

-- Dia da Fundação do Hospital

- Natal e Páscoa

- Festinhas de confraternização após o término de cursos. 
2. Satisfação e ajustamento da equipe de enfermagem na função e no ambiente de trabalho.

Tendo como premissa que o grau de humanização do atendimento varia na razão direta do grau de satisfação e ajustamento dos funcionários no trabalho, fizemos um estudo exploratório desses fatores.

Para a coleta de dados, utilizamos o questionário preenchido, de preferência, por entrevistador.

Não sendo possível abranger toda a população, colhemos uma amostra, ao acaso, de 26 enfermeiras, 33 auxiliares de enfermagem, e 44 atendentes de enfermagem do Hospital, excluindo o pessoal doj ambulatórios.

Os resultados, dados em porcentagem, constam no gráfico n. ${ }^{\circ} 1$, em anexo.

Constatamos que, na amostra estudada, os auxiliares de enfermagem revelaram maior índice de satisfação na função, vindo, a seguir, as enfermeiras e por último os atendentes.

A situação dos auxiliares de enfermagem talvez se explique pela coerência entre as atividades ensinadas e as profissionais, na vida prática; as enfermeiras nem sempre encontram essa continuidade ou coerência entre a escola e a vida profissional, fator que poderá levá-las a um maior grau frustração e desajustamento, além disso, o seu trabalho não é devidamente valorizado. Os atendentes, em grande parte, não exercem a função por escolha, mas por necessidade ou falta de oportunidade de abraçar aquela de que gostariam, (escolha $56,8 \%$ ). No entanto, seu maior nível de aspiração incide sobre a função de auxiliar de enfermagem, $(36,36 \%)$.

Quanto à satisfação no local de trabalho, existe inversão com relação aos atendentes, ficando as enfermeiras em último lugar. Talvez essa relação se explique em função do maior contato e responsabilidade da enfermeira quanto aos problemas e ocorrências do seu setor de trabalho, pela posição de liderança que sempre ocupa. Outra hipótese seria pertinente ao grau de instrução. Quanto mais alto o nível de instrução, maiores seriam as exigências e necessidades das pessoas.

3. Auto-avaliação do atendimento humano prestado aos pacientes e seus familiares.

A auto-avaliação do atendimento humano prestado aos pacientes foi feita através da $2 .^{\mathrm{a}}$ parte do questionário aplicado à amostra acima referida. Consistiu de uma avaliação global com relação às variáveis de atenção, delicadeza e compreensão com os pacientes e com os familiares, em termos dcs graus: ótimo, bom, regular e mau. 
Os dados revelaram que a auto-avaliação é mais positiva com relação aos pacientes do que aos familiares. A maioria concorda que os familiares pertubam o andamento normal do serviço e que, em primeiro lugar, se deve ter tranquilidade no trabalho. As enfermeiras embora não aceitem bem a presença dos familiares e suas indagações, sabem que têm obrigaçōes para com eles $(92,32 \%)$.

4. Avaliação dos pacientes

A natureza do relacionamento do paciente com a equipe de enfermagem fornece-lhe elementos ímpares para aquilatar o grau de humanização do seu atendimento. Seus informes foram coletados através de entrevista dirigida, realizada numa amostra de 90 pacientes, com tempo de internação mínimo de 1 semana.

A avaliação global foi idêntica à auto-avaliação, no tocante às variáveis e graus; apenas incluíram a informação: com exceção ou sem exceção. As categorias funcionais foram avaliadas separadamente.

Dentre as variáveis destinadas a testar as resposta da $1 .{ }^{\mathrm{a}}$ parte, foram incluídas uma referente ao direito de informação e outra ao respeito à identidade. Discordam ser conduzidos a exames sem serem informados para onde iriam $72,23 \%$. O restante admitiu tal comportamento da enfermagem.

Apenas $64,43 \%$ dos pacientes afirmam que são chamados sempre pelo nome. Com frequência, são chamados por uma relação de parentesco irreal, vazia, ou por um número.

Segundo Erich Fromm, o avanço tecnológico desencadeou um processo de quantificação e abstratificação que extrapolou a esfera do político, da produção e da econômia, invadindo as interelações humanas. Na equipe de saúde esse fenômeno também está presente; o paciente delxa de ser um pessoa para ser "um caso interessante", (uma úlcera, uma estenose mitral etc...) ou um número. Com frequência a enfermagem planeja e distribui tarefas em função do rúmero de banhos de leito, curativos, inalações etc... O paciente individualizado, com seus problemas, temores e necessidades, não é sempre levado em conta. Grande ênfase recai sobre os cuidados técnicos: $57,78 \%$ dos pacientes afirmam que o pessoal de enfermagem presta só cuidados técnicos, enquanto que $30 \%$ do pessoal de enfermagem admite que o mais importante são os cuidados técnicos.

\section{Avaliação dos familiares}

Os familiares dos pacientes,levados pelas preocupações e ansiedades, solicitam muito a equipe de enfermagem, principalmente as 
enfermeiras. Por esse motivo, também foram convidadcs a avaliar a equipe.

O questionário, aplicado a uma amostra de 55 familiares, foi idêntico ao dos pacientes, na $1 .^{\mathrm{a}}$ parte, na segunda foram introduzidas as variações necessárias. Além disso, foi incluída uma pergunta em aberto scbre o porquê da satisfação ou não satisfação com relação ao atendimento do paciente.

Os dados fornecidos mostraram, embora mais atenuadamente, as deficiências apontadas na auto-avaliação.

No Hospital, é função da enfermeira orientarr os familiares e car-lhes as informaçōes gerais sobre cs pacientes. Percebeu-se, em cbservaçōes ocasionais, que esta atribuição lhes é muito ingrata. Embora apenas $16 \%$ das enfermeiras tenham admitido que evitam falar com os familiares do paciente, cerca de $46 \%$ deles percebem o fato. Um entrevistado afirmou que a atitude da enfermeira com os familiares os mantém à distância.

Talvez, algumas vezes, a fuga do relacionamento com os familiares se explique pelo acúmulo de trabalho e falta de tempo. No entanto, parece mais plausível ser causada pela insegurança decorrente da falta de preparo para o atendimento dos familiares durante o período escolar. Durante o curso de enfermagem, a família foi considerada em função do doente. Os temores, ansiedades, necessidades de informação dos familiares a respeito do paciente não foram devidamente considerados, ou se foram, faltou a eperiência durante os estágios, pois estes são feitos fora do horário de visitas. Essa incompreensão dos problemas dos familiares dos pacientes não é observada só entre os profissionais da enfermagem... Aliás, parece ser tendência geral a atenção exclusiva para o objeto central do trabalho especializado. A propósito, na época do levantamento, ouviu-se uma professora de pré-primário dizer: "Detesto a reunião com as mães, as crianças não oferecem problema algum, mas as mães perturbam... Seria melhor lecionar se todas as crianças fossem órfãos..."

Ao citar exceções do atendimento ótimo ou bom, os entrevistacos fizeram questão de relatar os fatos ocorridos. Todos ressaltavam a indelicadeza, impaciência e imcompreensão demonstradas pelo profisisonal. Tal comportamento teve maior repercussão quando se tratava de enfermeira. Portanto, exige-se mais de quem tem mais conhecimentos.

IV - CONCLUSÃO

O hospital, por sua natureza, reune pessoas angustiadas, temerosas e inseguras, que demonstram alto nível de tensão emocional. Este favorece, muitas vezes, comportamentos irracionais. Essa irra- 
cicnalidade é admissível e compreensível no comportamento de pacientes e familiares. A equipe de enfermagem deveria ter condições e estar preparada para compreendê-los e para agir sempre racionalmente, evitando assim os frequentes atritos. No entanto, essa equipe é constituída também de seres humanos sujeitos à tensão provocada pelas emoçōes e o cansaço. Daí a importância da manipulação dos fatores que condicinam as possibilidades de humanização do ambiente de trabalho.

A humanização, de acordo com o que evidenciaram os dados, configura-se na delicadeza, cortesia, paciência e compreensão. Essas atitudes são perfeitamente compatíveis com as interações formais, preconizadas pela sociedade atual. Portanto, as relações formais correspondem às expectativas do paciente e familiares.

Pelo exposto, concluímos que o exercício da enfermagem requer não só conhecimentos técnicos mas também um alto nível de compreensão do homem, seus problemas e aspirações. Cada profissional deveria educar-se no espírito de um humanismo "bastante largo para acertar tudo o que é do homem, bastante livre para respeitar as diversidades na unidade, bastante forte para fazer progredir a obra comum no respeito dessas diversidades".

O comportamento humano exige auto-disciplina. "Sem o domínio de si mesmo, nada significa para o homem a pujança da ativicade interior ou a autoridade do poder". "Aquele que não sabe acrescentar sua vontade à sua força, não tem força”. 


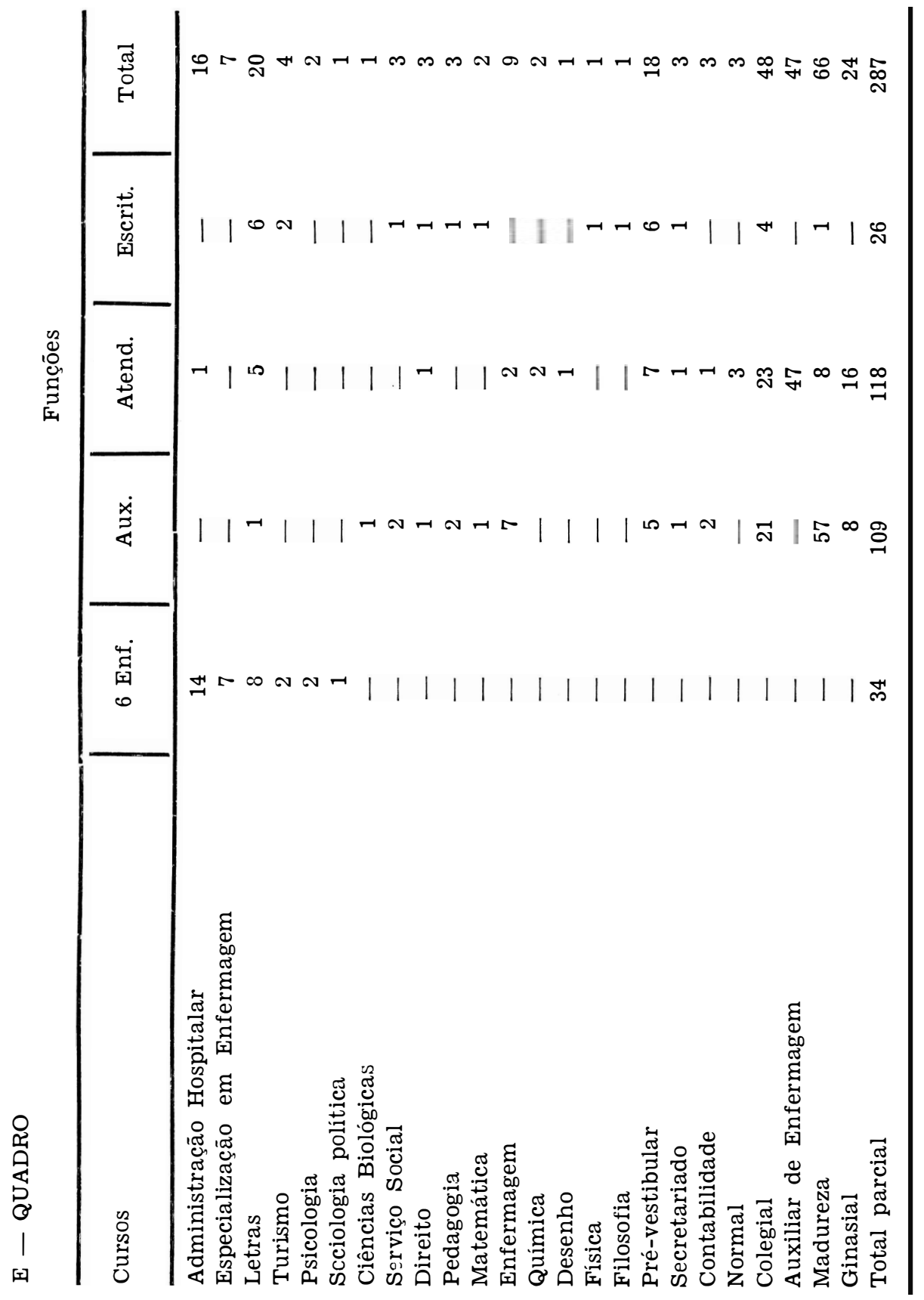


BIBLIOGRAFIA

ARGYLE. Michael - A Psicologia e os problemas sociais - Zahar, Rio, 1967.

ASCH, Solomon - Psicologia Social - 2. ${ }^{\text {a }}$ ed., Nacional, S. Paulo, 1966.

AZEVEDO, Fernando de - Na Batalha do Humanismo - Melhoramentos - São Paulo, 1952.

CAMIGNOTTO, Antonio - A Humanização do Hospital - Fator de Eficiência, in Revista Paulista de Hospitais, n. ${ }^{\circ}$ 11, novembro, 1.972.

FROMM, Erch - Psicanálise da Sociedade Contemporânea - 3. ${ }^{\mathrm{a}}$ ed., Zahar. Rio, 1963. 